\title{
Da familia de Nazaré aos tempos de hoje: a familia migrante
}

\author{
Gabriel Antunes Ferreira de Almeida*
}

Resumo: O artigo faz inicialmente um apanhado histórico do fenômeno da migração, a partir das famílias migrantes na história do povo de Israel. Destaca, em seguida, os ensinamentos e as práticas da lgreja em favor dos migrantes e, sobretudo, das famílias migrantes. Através da recordação e do estudo das mensagens dos últimos papas voltadas ao assunto, o autor pretende apurar o olhar cristão para esses últimos de nossas sociedades, para tentar suscitar compaixão e uma ação efetiva em favor da pessoa de Cristo no pobre.

Palavras-chave: Família e migrações; Migrantes e refugiados; Ensinamentos pontifícios.

Abstract: The article starts exposing a historic summary of the migrations phenomenon, since the migrant families in the history of the people of Israel. The writer emphasizes the teachings and practices of the Church in favor of the migrants and, most of all, of the migrant families. By means of recalling and studying the messages of the last Popes about this question, the author intends to direct the Christian regard in favor of these last ones of our societies, in order to stir up compassion and and effective action in favor of the person of Christ in the poor.

Key-words: Family and migrations; migrants and refugees; Pontifical teachings.

* Bacharel em Relações Internacionais (PUC-Rio, 2010). Mestre em Fundamentos e Prospectivas de Cultura de Unidade, com especialização em Ontologia Trinitária (Istituto Universitario Sophia, Florença, Itália, 2013). Doutorando em Filosofia (Università degli Studi di Perugia, Itália). Membro do Grupo de Estudos Filosóficos sobre Ontologia Trinitária do Istituto Universitario Sophia. Tutor dos Cursos de Gnoseologia e História da Filosofia I na Università degli Studi di Perugia. 
Desde os tempos mais antigos os homens e mulheres que habitam nessa terra se locomovem pela sua superfície em busca de melhores condições de vida. Antes, quando uma área já não apresentava a abundância de alimentação ou a segurança necessária, esses inúmeros grupos humanos buscavam outros espaços geográficos que pudessem dar-lhes condições para a vida. E hoje não estamos indiferentes a esses desejos mais que naturais de toda pessoa: buscar para si um mínimo de dignidade. Se antes as barreiras poderiam ser geográficas e climáticas, hoje as barreiras são feitas de cercas de arame, policiais armados e cães que ladram. Não nos cabe analisar as mudanças que a História fez nesses séculos, pois o objetivo desse artigo é analisar um fenômeno específico: dentro dessas mudanças continuamos a ter famílias que se aventuram em busca de melhor dignidade humana e que sofrem, nos próprios corpos, as dores do arame farpado que divide pais de filhos, e maridos de suas esposas. Iremos traçar nesse artigo um pequeno estudo, ou melhor, apurar nosso olhar cristão para esses últimos de nossas sociedades para tentar suscitar um olhar e uma ação ética para o Cristo no pobre, o Cristo que, no colo de sua mãe, ainda chora nas pessoas do que foram ou são obrigados ao desterro no Egito.

\section{O fenômeno da migração}

É necessário já explicar o porquê da escolha da palavra migração (e não imigração), que fazemos tanto para o título como para o texto desse artigo. A palavra migração geralmente vem usada para indicar os movimentos que se dão dentro de um território nacional definido. $\mathrm{E}$ a palavra imigração para indicar os movimentos que ocorrem entre diferentes países. A nossa escolha é puramente política, no sentido amplo da palavra, para exaltar o fim último da política que é o bem comum. Ou seja, estamos aqui indicando que o planeta Terra é único e que a família humana se alarga, ao olhar cristão ${ }^{1}$, para toda a humanidade. A dignidade da criatura humana se estende sobre toda a terra (cf. Gn 10) e sobre todas as gerações (cf. Gn 5).

Feita essa ressalva, entremos na questão inicial: como se dá esse fenômeno da migração. Como primeiro passo, deveremos entender como

1 Para aprofundar essa visão da unidade da família humana, recomenda-se a primeira parte (Aspectos Bíblicos) do Capítulo IX do Compêndio da Doutrina Social da Igreja, em seus pontos: A unidade da família humana; Jesus Cristo; protótipo e fundamento da nova humanidade e A vocação universal do cristianismo. 
surge a figura do imigrante ${ }^{2}$. Uma das características principais do sistema internacional que temos hoje é a presença das fronteiras. O surgimento dessas é consequência do desenvolvimento do Estado como um dos atores desse sistema. Para alguns teóricos das relações internacionais o Estado é o ator central e uma de suas características é ser delimitado pela fronteira. O confim, que pode ser divisão, pode servir também para relação. Pode assinalar o limite, mas também o desejo de superá-lo.

O confim é um elemento presente desde os mais remotos tempos em nosso planeta. No antigo Egito, por exemplo, era necessário marcar os limites do terreno com pedras para que a cheia do Nilo não atrapalhasse uma nova demarcação. A fronteira para os antigos não era vista como um elemento linear, mas sim como uma região. Já na época medieval tardia e início da modernidade, essa ideia de confim/fronteira sofre uma alteração. $\mathrm{O}$ desafio presente nessa época era a fragmentação das antigas ordens imperiais e a formação de Estados soberanos. A fórmula rex in regno suo est imperator (o rei é o imperador de seu reino) é a exemplificação da demarcação jurídica do Estado moderno. Já no mundo contemporâneo, surge uma ideia nova para o conceito de fronteira/confim. Não é mais tido como o espaço da defesa ou delimitação do espaço da conquista, mas sim como elemento de divisão ${ }^{3}$. É a presença de uma fronteira/confim que transforma um ser humano em estrangeiro. É a sua presença que também pode separar inúmeras famílias. Como sinal de divisão, podemos

2 Usamos a palavra imigrante para demarcar a situação em que vivem hoje essas famílias, já destacando que há nesse momento histórico a dificuldade da livre circulação de pessoas. É interessante notar que há uma grande diferença entre a livre circulação de pessoas e suas barreiras e a livre circulação de mercadorias e capitais (esses últimos cada vez mais desregularizados pelos mercados financeiros internacionais). A diferença dessas circulações poderia ressaltar interpretações opostas do fenômeno da globalização. Para aprofundar esse tema, sugerimos: BARTELSON, J., Three Concepts of Globalization, International Sociology, June 2000, 15: 180-196; BARTELSON, J. (1998) 'Second Natures: Is the State Identical with Itself?', European Journal of International Relations 4(3): 295-326; SCHOLTE, J.-A. (1993) 'From Power Politics to Social Change: An Alternative Focus for International Studies', Review of International Studies 19(1): 3-21; SCHOLTE, J.-A. (1996) 'The Geography of Collective Identities in a Globalizing World', Review of International Political Economy 3(4): 565-607; SCHOLTE, J.-A. (1997) 'Global Capitalism and the State', International Affairs 73(3): 427-452; BAUMAN, Z. (1998) Globalization. The Human Consequences. Cambridge: Polity Press. trad. port. Globalização: as consequências humanas. Rio de Janeiro: Jorge Zahar, 1999.

3 Para aprofundar o aspecto da construção de fronteiras e um novo modelo de relações internacionais, no aspecto do diálogo entre diferentes culturas - no qual retratamos essa nossa análise de confim -, sugerimos: FERRARA P., Limes. I/ confine nell'era postglobale. Sophia - Ricerche su i fondamenti e la correlazione dei saperi III (20112), p. 183-194. 
contar várias construções de muros que hoje separam as fronteiras. Por exemplo: entre Hungria e Sérvia, Reino de Marrocos e Frente Polisário, Arábia Saudita e Iraque, Israel e Palestina, Estados Unidos e México, Grécia e Turquia, Espanha e Marrocos, Índia e Bangladesh.

A Agência para Refugiados das Nações Unidas (UNHCR - sigla em inglês), em seu último relatório sobre os dados dos refugiados, mesmo não apresentando um número de famílias refugiadas, demonstra como são grandes os grupos humanos que estão nessa situação. No ano de 2014, são exatamente 59,5 milhões de pessoas forçadas a saírem de suas terras de origem. Dessas, 19,5 milhões eram refugiadas, 38,2 milhões eram pessoas deslocadas internamente, e 1,8 milhão eram requerentes ao asilo. Somente no ano de 2014 houve um acréscimo, em relação ao ano de 2013, de 13,9 milhões de pessoas deslocadas forçadamente por causa de conflito e perseguição ${ }^{4}$. É por essa razão que o Papa Francisco rezou na Via Crucis desse ano:

O Croce di Cristo, ancora oggi ti vediamo nei volti dei bambini, delle donne e delle persone, sfiniti e impauriti che fuggono dalle guerre e dalle violenze e spesso non trovano che la morte e tanti Pilati con le mani lavate... O Croce di Cristo, ti vediamo ancora oggi nel nostro Mediterraneo e nel mar Egeo divenuti un insaziabile cimitero, immagine della nostra coscienza insensibile e narcotizzata... ${ }^{5}$

\section{A família migrante e a história do povo de Deus até os dias de hoje}

$\mathrm{Na}$ história do povo hebraico, a figura do estrangeiro é posta ao lado de extratos sociais que seriam os mais frágeis, como a viúva e o órfão (Ex 22,21: na continuação, a quem não afligir), e o pobre (Ex 22,24: "Se emprestares dinheiro a um compatriota, ao indigente que está em teu meio, não agirás com ele como credor que impõe juros"). É o próprio JHWH a recordar aos hebreus esses extratos da sociedade que

4 UNHCR, Global Trends Forced Displacement in 2014. UNHCR, 2015.

5 Disponível em: <http://www.avvenire.it/Papa_Francesco/Pagine/preghiera-papacroce-di-Cristo-via-crucis-colosseo.aspx>. Acesso em: 26 mar. 2016. "Ó, Cruz de Cristo, ainda hoje te vemos nos rostos das crianças, das mulheres e das pessoas, fracas e amedrontadas que fogem das guerras e violências e encontram somente a morte e tantos Pilatos com as mãos lavadas. [...] Ó, Cruz de Cristo, te vemos em nosso Mediterrâneo e no mar Egeu que tornaram-se insaiáveis cemitérios, imagem de nossa consciência insensível e narcotizada". 
poderiam se encontrar de alguma maneira mais vulneráveis e, por isso, precisando de uma atenção particular. Apresenta-se um JHWH que dá atenção àquelas minorias. Não direcionar a devida atenção ao estrangeiro por parte de Israel é, ao mesmo tempo, escolha de outro deus e traição das origens de Israel como sociedade tribal - fundada sobre relação de parentesco -, na qual os relacionamentos de igualdade e solidariedade têm um papel fundamental. É importante também a cultura de acolhida que há em uma sociedade de origem tribal, na relação com o forasteiro que recebe a proteção de uma família.

Outras passagens, igualmente importantes, poderemos encontrar em Dt 24,17 ("Não perverterás o direito do estrangeiro e do órfão, nem tomarás como penhor a roupa da viúva"), em Dt 27,19 ("Maldito seja aquele que perverte o direito do estrangeiro, do órfão e da viúva! E todo povo dirá: Amém!") e em Dt 14,28-29 (“A cada três anos tomarás o dízimo da tua colheita no terceiro ano e o colocarás em tuas portas. Virá então o levita [pois ele não tem parte nem herança contigo], o estrangeiro, o órfão e a viúva que vivem nas tuas cidades, e eles comerão e se saciarão. Deste modo JHWH teu Deus te abençoará..."). Justifica-se assim a figura do estrangeiro com as células mais frágeis da sociedade, a viúva e o órfão. Esses dois últimos são parte de uma família já destruída ou carente. Ou seja, a figura do estrangeiro, já desde a história antiga do povo hebreu, é ligada às figuras mais frágeis das famílias.

Outra história ligada ao Primeiro Testamento e interessante para a nossa análise é a de Abraão e Sara. A história dessa família começa em Gn 11,27. As primeiras palavras são de sua genealogia, e logo depois no capítulo 12 há um dos mais belos diálogos que existem no Primeiro Testamento. JHWH ordena a Abraão que parta daquela terra na qual vivia desde pequeno, pede para deixar a família de seu pai. Assim, Abraão parte para Canaã, junto com sua mulher e Lot. Depois da promessa da terra à sua posteridade $(G n 12,7)$, Abraão deve deixar a região por causa da fome e ir para o Egito. Quantas são as famílias que hoje fazem esse mesmo caminho de desenraizamento? Quantas são hoje as famílias de Nazaré que também têm que se refugiar no Egito?

Mateus nos relata a fuga da Sagrada Família para o Egito (Mt 2,1322). José foi avisado por um anjo do Senhor do perigo do rei Herodes e assim foi indicado que deveriam ir para o Egito. Pela passagem bíblica, José acorda e em seguida pega a sua família e parte para o exílio. Eram como que refugiados políticos daquela época, já que o rei Herodes queria 
matar Jesus. E somente depois da aparição do anjo pela segunda vez, avisando a José que em Israel não havia mais perigo, ele retorna com sua família para a sua terra. Mas nem tudo se mostra fácil para José, pois the é dado o aviso de que Arquelau reinava na Judéia, e por isso vai morar em Nazaré. Vale relembrar as palavras de Pio XII que recorda o desterro da Sagrada Família como modelo de toda a família refugiada:

A familia de Nazaré no exilio, Jesus, Maria e José, emigrantes no Egito e lá refugiados para se subtraírem à ira de um ímpio rei, são o modelo, o exemplo e o apoio para todos os prófugos de qualquer condição que, ameaçados pela perseguição ou pelas necessidades, se veem obrigados a abandonar a pátria, os queridos parentes, os vizinhos, o afeto dos amigos, e a deslocar-se para terras estrangeiras. ${ }^{6}$

E tantas vezes essas famílias são destruídas já bem antes, restando às crianças fugirem sozinhas de suas terras. Em 2014, 34.300 foram os pedidos de asilo feitos por crianças separadas ou desacompanhadas, recolhidas em 82 países. A grande maioria era do Afeganistão, Eritreia, Síria e Somália. Foi o maior número registrado desde que o ANHCR começou a recolher os dados em 2006. E, sempre em 2014, as crianças representavam 51\% de toda a população de pessoas forçadamente deslocadas?

Poderemos listar um grande elenco de razões pelas quais fogem essas crianças. Basta, porém, um exemplo das mazelas sofridas por elas: a realidade da criança soldado. Não se tem um número exato, mas ONGs que trabalham nesse setor estimam que mais de 300.000 menores de 18 anos estão atualmente atuando como crianças soldados no mundo. A maioria desses tem idade de 15 a 18 anos, mas já se registram muitos menores de 15 anos presentes nas frentes de batalha. O fenômeno aumentou porque mudou a natureza da guerra. A guerra hoje é prevalentemente de natureza étnica, religiosa e nacionalista, e os senhores de guerra não têm que se preocupar com as Convenções de Genebra ${ }^{8}$ ou qualquer outro tratado que vincula Estados. A Igreja sempre esteve junto às iniciativas promovidas para tentar acabar com essa realidade. No

6 PIO XII. Constitutio Apostolica Exsul Familia. Disponível em: <http://w2.vatican.va/ content/pius-xii/la/apost_constitutions/documents/hf_p-xii_apc_19520801_exsulfamilia.html>. Acesso em: 26 mar. 2016.

7 UNHCR. Global Trends Forced Displacement in 2014. UNHCR, 2015.

8 As Convenções de Genebra são decisões de inúmeros encontros (1864, 1906, 1929, 1949), além dos protocolos (1977 e 2005) que versam sobre o Direito Humanitário Internacional. 
discurso pronunciado durante a conferência europeia sobre a utilização de crianças como soldados, em Berlim (1999), Monsenhor Giuseppe Bertello, então observador permanente da Santa Sé nas Nações Unidas, em Genebra, lembrou alguns dos aspetos mais trágicos da experiência de crianças soldados: a não presença de um guia; a falta de uma formação adequada que não faça reconhecer outro parâmetro que não seja o da guerra; a impossibilidade de viver na paz ${ }^{9}$. João Paulo II teve várias oportunidades de falar sobre o tema das crianças soldados e, em particular, no Discurso para o Dia Mundial da Paz, de 199610. Referindo-se às crianças obrigadas a tornarem-se protagonistas da violência da guerra, expressou a sua profunda dor, chamando as instituições e organizações católicas a dedicarem-se aos menores, ajudando a infância a redescobrir o afeto do amor de Deus que se fez homem e que, morrendo, deixou ao mundo o seu dom de paz.

\section{O caminho da Igreja contemporânea na questão da migração e família}

Foram muitos os momentos em que a Igreja destacou o papel importante das famílias no processo de migração. Faremos um breve excursus de alguns momentos mais significativos em que a Igreja, através da voz dos papas e dos órgãos encarregados, fez referência específica ao tema da migração e da família.

Na mensagem para o Dia Mundial do Migrante, no ano de 197911, São João Paulo II, referindo-se ao pessoal que trabalha nos organismos eclesiais envolvidos com os migrantes, já destacava que eles conhecem mais que outros a dor e o sofrimento que carregam essas pessoas obrigadas a saírem dos seus países, principalmente as mulheres e crianças. O importante dessa mensagem é o alerta, mesmo que indireto, que o

9 Discurso da Santa Sé no encontro "European Conference on the Use of Children as Soldiers", Berlim, 18 de outubro de 1999.

10 JOÃO PAULO II, Mensagem para o Dia Mundial da Paz, de 1996, nn. 3-4. Disponível em: <http://w2.vatican.va/content/john-paul-ii/pt/messages/peace/documents/hf_.jpii_mes_08121995_xxix-world-day-for-peace.html>. Acesso em: 26 mar. 2016.

11 Dez anos antes, o Concílio Vaticano II, em seu decreto Apostolicam Actuositatem sobre o Apostolado dos Leigos, destaca que, ao regulamentar a migração, deve-se sempre salvar a convivência familiar, e enumera algumas obras de apostolado familiar, como a hospitalidade com os estrangeiros (AA, n. 11). 
Papa faz sobre a situação dos membros das famílias mais vulneráveis: mulheres e crianças ${ }^{12}$.

Já no ano seguinte, São João Paulo II dedica a mensagem do Dia Mundial do Migrante especialmente à família ${ }^{13}$. Adverte que a migração pode atingir a família especialmente naquilo que tange a sua estabilidade e coesão. Pois o fenômeno da migração pode levar a uma separação forçada de maridos e esposas. O desafio que daqui surge é o reagrupamento familiar ${ }^{14}$, que naquela época já começava a ser motivo de atenção das rodadas multilaterais de negociações internacionais. Tal separação poderia ser vista como um dos efeitos negativos das migrações forçadas. Além das condições miseráveis dos lugares que os migrantes deixam para trás, há ainda a busca desenfreada de lucro por parte dos demandantes de mão de obra que buscam homens e mulheres sós. Tal cenário não ajuda na construção do lar, além de causar problemas para os filhos, que não têm o núcleo familiar composto para criar um ambiente necessário para a educação.

E, mesmo que a família consiga migrar unida, o cenário pode apresentar outras dificuldades, citadas pela mensagem: o não conhecimento da nova língua, os costumes diversos com as consequentes dificuldades de adaptação, a habitação muitas vezes imprópria e precária (n. 2). Tal cenário cria isolamento entre as famílias autóctones e as que migram, podendo chegar até a apresentar sinais de racismo. Esses podem claramente refletir sobre a vida conjugal da família migrante, como entre os pais e os filhos, ameaçando a harmonia entre os membros. Hoje, tal cenário corrobora a tese de que vários terroristas radicais islâmicos são nascidos e criados na Europa, a chamada segunda geração. O que poderia ter causado a grande conquista de corações e mentes desses jovens a essa causa radical é o sentimento de raiva que os mesmos sentem pelos seus pais, que não foram suficientemente corajosos para gritar contra

12 Disponível em: <http://w2.vatican.va/content/john-paul-ii/pt/messages/migration/ documents/hf_jp-ii_mes_19791201_world-migration-day-1979.html>. Acesso em: 28 mar. 2016.

13 Disponível em: <http://w2.vatican.va/content/john-paul-ii/pt/messages/migration/ documents/hf_jp-ii_mes_19801201_world-migration-day-1980.html>. Acesso em: 28 mar. 2016.

14 Na mensagem para o Dia Mundial do Migrante, de 1996, São João Paulo II retorna a esse tema dentro do cenário dos imigrantes "ilegais": "É necessário evitar recorrer ao uso de regulamentos administrativos, que visam restringir o critério da pertença familiar, com a consequência de impelir injustificadamente fora da legalidade pessoas, às quais nenhuma lei pode negar o direito à convivência familiar.". Disponível em:<http://w2.vatican.va/content/john-paul-ii/pt/messages/migration/documents/hf_jpii_mes_25071995_undocumented_migrants.html>. Acesso em: 23 mar. 2016. 
os preconceitos sofridos quando apenas migraram para a Europa, e dos quais a segunda geração ainda sente os efeitos, sofrendo eles mesmos as mesmas discriminações. Proféticas são as palavras de São João Paulo II, no dia 31 de maio daquele ano, para os poloneses migrados para a França, sobre o processo de integração, na liberdade e no respeito:

A integração é sem dúvida um problema importante para todos e necessário. Hoje, ninguém se pode fechar no próprio "gueto". Deveis servir o País, no qual viveis, trabalhar para ale, amá-lo, contribuir para o seu progresso, desenvolvendo-vos a vós mesmos, a vossa humanidade, tudo o que está em vós, que vos forma, sem falsificar, sem cancelar aquelas linhas que se prolongam no passado e, através dos vossos pais e das gerações, talvez já muitas, se radicam numa realidade mais modesta e mais pobre daquela na qual viveis, todavia grande e preciosa ${ }^{15}$.

Em 1981, São João Paulo II, na sua Exortação Apostólica Familiaris Consortio, enumera, entre vários casos de situações difíceis de pastoral familiar, aquele das famílias migrantes. Exalta que essas devem encontrar na Igreja a sua pátria, recordando a função de unidade na diversidade da comunidade de Cristo. Exorta que as famílias divididas possam se encontrar o mais rápido possível e aponta para soluções que busquem a justiça social. Os temas dessa exortação, além dos avanços realizados naqueles anos, serão relembrados na mensagem do Dia Mundial do Migrante, no ano de $1982^{16}$.

Na mensagem do Dia do Migrante, em 1986'ㄱ, São João Paulo II chama a atenção para a família como a estrutura mais frágil, vulnerável e investida dos aspectos negativos da migração. Em todo o número 2 da mensagem, o Papa apresenta a grande ferida que pode causar o fenômeno da migração na família: é atingida na sua missão de transmitir os valores da vida e do amor. E continua destacando os fatores estruturais que podem causar tal cenário: trabalhos estacionários, irregulares, marginação da mulher migrante, condições de habitação, marginalização na participação sociopolítica.

15 Disponível em: <http://w2.vatican.va/content/john-paul-ii/pt/speeches/1980/may/ documents/hf_jp-ii_spe_19800531_polacchi-parigi.html>. Acesso em: 27 mar. 2016.

16 Disponível em: <http://w2.vatican.va/content/john-paul-ii/pt/messages/migration/ documents/hf_jp-ii_mes_19820904_world-migration-day-1982.html>. Acesso em: 27 mar. 2016.

17 Disponível em: <http://w2.vatican.va/content/john-paul-ii/it/messages/migration/documents/hf_jp-ii_mes_19860815_world-migration-day-1986.html>. Acesso em: 28 mar. 2016. 
Já no ano de 1993, São João Paulo II, por causa do Ano Internacional da Família, dedica sua mensagem do Dia Mundial do Migrante ao tema família e migração. Um ponto importante, que nos anos anteriores não havia sido tão acentuado, e que destacamos aqui, é o papel do Estado. Esse tem a obrigação de tutelar as famílias migrantes, e dar atenção às necessidades peculiares. Especialmente o Estado deverá criar mecanismos contra qualquer forma de discriminação e marginalização, com a finalidade de um desenvolvimento familiar que respeite a dignidade humana. Na mensagem ${ }^{18}$ para o ano de 1995, o Papa coloca o acento sobre a situação das mulheres, esposas ou filhas, e os graves riscos que elas poderiam sofrer com o fenômeno da migração.

No Angelus de 06 de julho de $2003^{19}$, São João Paulo II relembrava que a Convenção internacional sobre a proteção dos direitos dos trabalhadores migrantes e de seus familiares ${ }^{20}$, do ano de 1990, tinha entrado em vigor, e destacava que esse processo legislativo era um passo importante para considerar o migrante como pessoa ligada à sua família. Esse mesmo tema será recordado mais adiante na Erga migrantes caritas Christi (A caridade de Cristo em relação aos migrantes), no artigo segundo, no primeiro parágrafo do capítulo ordem jurídico-pastoral.

Com efeito, no dia 01 de maio de 2004, São João Paulo II aprovou um documento do Conselho da Pastoral para os Migrantes e os Itinerantes (sendo publicado pelo mesmo em 03 de maio de 2004). O título do documento é Erga migrantes caritas Christi (A Caridade de Cristo em relação aos migrantes). Na sua segunda parte ao tratar da realidade da pastoral da acolhida, em seu número 47, indica que a pastoral deve dar muito espaço à família migrante, compreendida como "Igreja doméstica" ${ }^{21}$, aos grupos bíblicos familiares, à oração comum ${ }^{22}$. Depois

18 Disponível em: <http://w2.vatican.va/content/john-paul-ii/it/messages/migration/documents/hf_jp-ii_mes_19940810_world-migration-day-1995.html>. Acesso em: 25 mar. 2016.

19 Disponível em: <http://w2.vatican.va/content/john-paul-ii/it/angelus/2003/documents/ hf_jp-ii_ang_20030706.html>. Acesso em: 27 mar. 2016.

20 Texto em Inglês disponível em: <http://www2.ohchr.org/english/bodies/cmw/cmw.htm>. Acesso em: 27 mar. 2016.

21 Essa realidade será acentuada várias vezes como, por exemplo, na mensagem do Dia Mundial do Migrante, em 1987 (n.4 - c). Disponível em: <http://w2.vatican.va/ content/john-paul-ii/it/messages/migration/documents/hf_jp-ii_mes_19870805_worldmigration-day-1987.html>. Acesso em: 28 mar. 2016.

22 Disponível em: <http://www.vatican.va//roman_curia/pontifical_councils/migrants/ documents/rc_pc_migrants_doc_20200405_erga-migrantes-caritas-christi_it.html>. 
é explicado, mais adiante no ponto 49 , o porquê dessa recomendação. A Igreja recomenda que os grupos familiares de migrantes sejam reunidos, se assim for possível, em comunidades que perpetuem seus ritos e sua identidade religiosa, para não sofrerem tanto o peso de inúmeros desenraizamentos. Mas sempre lembra a importância da comunhão e recíprocos momentos de conhecimento entre a comunidade migrante e as comunidades locais.

Depois o documento enfrenta um problema que é muito comum na realidade de duas pessoas que se preparam ao matrimonio, a família mista. Pois esse é uma realidade impulsionada pelo fenômeno da migração. Como regra geral a Igreja, com exceção de casos particulares, não aconselha o matrimônio entre pessoas de religião diversa, pelas dificuldades que isso pode comportar no relacionamento de fé entre o casal e na educação dos filhos ${ }^{23}$. Uma atenção especial foi feita para os casamentos entre cristãos e mulçumanos, nos números 67 e 68 .

Bento XVI fala, na sua mensagem para o Dia Mundial do Migrante e do Refugiado, de 2006, sobre o processo de "feminização" do fenômeno da migração, ou seja, sobre o fato de que as mulheres começaram a migrar mais do que os homens. Isso demonstra que a Igreja esteve sempre bem informada e na vanguarda dos fenômenos, expondo-os e trazendo soluções, sempre com a finalidade do bem comum de toda a família humana ${ }^{24}$.

Em 2007, o Papa Bento XVI escolhe a família como tema central de sua mensagem para o Dia Mundial do Migrante e do Refugiado ${ }^{25}$. Destacamos dois temas: a reunificação familiar e os estudantes. Para o primeiro caso, o Papa chama atenção aos campos de refugiados e à situação crítica de habitação em que essas famílias são colocadas, bem como aos inúmeros traumas pelos quais já passaram. E para o segundo,

Acesso em: 25 mar. 2016.

23 Para aprofundar tal passagem, sugerimos a leitura de João Paulo II, Exortação Apostólica pós-sinodal Ecclesia in Oceania. Disponível em: <http://w2.vatican.va/content/ john-paul-ii/pt/apost_exhortations/documents/hf_jp-ii_exh_20011122_ecclesia-inoceania.html>. Acesso em: 27 mar. 2016.

24 Disponível em: <http://w2.vatican.va/content/benedict-xvi/pt/messages/migration/ documents/hf_ben-xvi_mes_20051018_world-migrants-day.html>. Acesso em: 28 mar. 2016.

25 Disponível em: <http://w2.vatican.va/content/benedict-xvi/pt/messages/migration/ documents/hf_ben-xvi_mes_20061018_world-migrants-day.html>. Acesso em: 28 mar. 2016. 
dos filhos estudantes, adverte que a Igreja deverá fazer-se casa para esses filhos que estão longe de suas famílias, colocando-os em contato com famílias que possam hospedá-los. No ano seguinte, Bento XVI irá perpassar pelo assunto dos jovens e suas inúmeras situações como migrantes. Com muita sabedoria e com uma justa hermenêutica, Bento XVI se pergunta como a Igreja poderá ajudar esses jovens que têm em suas costas muitas dificuldades, como a carência do papel da família ou mesmo os conflitos causados entre a primeira e a segunda geração de migrantes. São os desafios que a Igreja não ignora e que não demora em responder, por meio de sua ação pastoral que vai ao encontro das necessidades reais dessa parte da família humana. Em 2010, Bento XVI ${ }^{26}$ chama a atenção para outro flagelo que se perpetua na situação da família migrante: as crianças. Já destacamos aqui a situação dramática sofrida por essas crianças que, como no caso da ameaça de tornarem-se soldados, escapam em busca de salvação e de um mínimo de dignidade. Porém, além de citar problemas, Bento XVI faz um chamado à importância das crianças nascidas em países diferentes de seus pais e à possibilidade que elas representam de ligação para o encontro dessas duas culturas.

\section{Conclusões}

São necessários coragem e dedicação para atuar com as famílias migrantes, pois elas não somente carregam dentro de si os desafios do fenômeno da migração como também do fenômeno particular da família. A atenção dada pela Igreja a esse caso particular foi sempre de vanguarda e com uma acurada visão de que a finalidade última de qualquer reflexão deve ser o bem comum e a unidade da família humana, em dignidade, liberdade e respeito.

E-mail do autor: gboerbon@gmail.com

26 Mensagem do Papa Bento XVI para o 96 Dia Mundial do Migrante e do refugiado. Disponível em: <http://w2.vatican.va/content/benedict-xvi/pt/messages/migration/ documents/hf_ben-xvi_mes_20091016_world-migrants-day.html>. Acesso em: 28 mar. 2016. 